AC ANNALS JOURNAL CLUB

\title{
A Dirty Little Secret Revealed: The Downside of Screening Tests
}

Ann Fam Med 2009;7:iii. DOI: 10.1370/afm.989.

The Annals of Family Medicine encourages readers to develop a learning community of those seeking to improve health care and health through enhanced primary care. You can participate by conducting a RADICAL journal club and sharing the results of your discussions in the Annals online discussion for the featured articles. RADICAL is an acronym for Read, Ask, Discuss, Inquire, Collaborate, Act, and Learn. The word radical also indicates the need to engage diverse participants in thinking critically about important issues affecting primary care and then acting on those discussions. ${ }^{1}$

\section{HOW IT WORKS}

In each issue, the Annals selects an article or articles and provides discussion tips and questions. We encourage you to take a RADICAL approach to these materials and to post a summary of your conversation in our online discussion. (Open the article online and click on "TRACK Comments: Submit a response.") You can find discussion questions and more information online at: http://www.AnnFamMed.org/AJC/.

\section{CURRENT SELECTION}

\section{Article for Discussion}

Croswell JM, Kramer BS, Kreimer AR, et al. Cumulative incidence of false-positive results in repeated, multimodal cancer screening. Ann Fam Med. 2009;7(3):212-222.

\section{DISCUSSION TIPS}

This analysis of a large cancer screening trial ${ }^{2}$ shows a negative aspect of cancer screening: the risk of a falsepositive test and resulting further invasive testing. As a background for reviewing this article, it might be helpful to think of a range of patients: patients who have experienced a false-positive test, patients who did or did not do screening and were found to have cancer, patients who want every test. You also may wish to use discussion of this article to prime participants to look for further publications of results from the Prostate, Lung, Colorectal, and Ovarian (PLCO) Cancer Screening Trial.

\section{DISCUSSION QUESTIONS}

- What question is addressed by the article? How does the question fit with what already is known on this topic?

- How strong is the study design for answering the question?

- What is the degree to which can the findings be accounted for by:

1. How participants were selected? The exclusion criteria and loss to follow-up? Are any biases likely to be important?

2. How outcomes were measured?

3. Confounding (false attribution of causality because 2 variables discovered to be associated actually are associated with a 3rd factor)?

4. How information was interpreted?

5. Chance?

- What are the main findings? How large is the effect for individual tests? What is the cumulative effect of repeated screening tests?

- What is the downside of screening tests in terms of follow-up invasive testing? What are possible other unintended consequences (both negative and positive)?

- What are the implications for how we talk with patients about screening tests?

- How might the forthcoming results of other outcomes of the PLCO trial affect how we interpret and use these findings?

- How transportable are the findings to your clinical setting? To other types of screening tests? What factors might affect this transportability?

- What are some next steps for applying the findings or answering other questions that this study raises?

\section{References}

1. Stange KC, Miller WL, McLellan LA, et al. Annals Journal Club: It's time to get RADICAL. Ann Fam Med. 2006;4(3):196-197. http:// annfammed.org/cgi/content/full/4/3/196.

2. Early Detection Research Group (EDRG). Prostate, Lung, Colorectal and Ovarian (PLCO) Cancer Screening Trial. http://prevention.cancer. gov/programs-resources/groups/ed/programs/plco. Accessed Feb 1, 2009. 